\title{
Design \& Analysis of Noise-Resilient Mix Data Rate Passive Optical Network Supporting Simultaneous Transmission of Both NGPON Standards
}

\author{
Ahmed Muddassir Khan, Sayed Hyder Abbas Musavi, Areez Khalil Memon, \\ Munsif Ali Jatoi, Syed Shahzeb Sami and Faizan-ur-Rehman \\ Faculty of Engineering, Science \& Technology (FEST), Indus University, \\ Karachi, Pakistan \\ ahmed.muddassir@indus.edu.pk,dean@indus.edu.pk, \\ areez.memon@indus.edu.pk,munsif.ali@indus.edu.pk, \\ shahzeb.sami@indus.edu.pk, faizan.rehman@indus.edu.pk
}

\begin{abstract}
In this paper, we have designed and investigated high data rate supported Wavelength Division Multiplexing Passive Optical Network (WDM-PON) architecture having 16 channels. In this proposed technique, Differential Quadrature Phase Shift Keying (DQPSK) modulated signal having 40 and 10 Gbps in downstream and Inverse Return-tozero (IRZ) modulated upstream is used with 20, 10 and 2.5 Gbps data rate. Transmission performance of proposed system has been compared on the basis of Bit error rate (BER) analysis at $10 \mathrm{Km}$ fiber length in both directions. Simulation results validate that proposed technique can simultaneously support high data rates for both next generation passive optical networks (NGPON) standards with good receiver sensitivity and noiseresilient transmission of all 16 high capacity WDM channels.
\end{abstract}

Keywords: Next Generation-Passive Optical Network (NGPON), Differential Quadrature Phase Shift Keying (DQPSK), Inverse Return-to-Zero (IRZ) and Bit error rate (BER)

\section{Introduction}

Recent industrial analysis forecasted that telecom operators have to deploy high data rate supported networks to tackle with drastic increase in bandwidth demands for upcoming broadband applications and profitability in business [1]. In this scenario technological roadmap is proposed by Full Service Access network (FSAN) which indicates the trends of high data rate supporting techniques in next generation passive optical networks NG-PON [2]. Due to low cost point-to-multi point design with high data rate, high quality and modern services supporting features, passive optical network (PON) is become most promising candidate in next generation access networks. Till now, several standards of PON have been introduced by ITU-T and IEEE such as ATM-PON (APON), Broadband-PON (BPON), Gigabit-PON (GPON), Extended GPON (XGPON), and Next Generation-PON 1(NG-PON 1) and the recent Next Generation-PON 2 (NG-PON 2) have been introduced [3-5]. Initially, FSAN launched APON and BPON during 2000 to 2002 and ITU-T standardized under the recommendations G.983.x and deployed till 2007. Then GPON was introduced and termed as a next generation access network and standardized under the ITU-T recommendation of G.984.x during 2001 to 2004 and remain deployed till 2012. Meanwhile, 10G-GPON (XGPON) have been standardized during 2007 to 2011 under the ITU-T recommendations of G.987.x and is being deployed

Received (May 6, 2017), Review Result (July 8, 2017), Accepted (August 25, 2017) 
from 2012 to 2015. Then FSAN and ITU-T started working up-gradation of XGPON to more improved PON and thus NGPONs have been emerged having Asymmetric 10Gbps downstream and 2.5 Gbps upstream transmission, it was just enhancement of TDMPON from existing GPON. But evaluation of NGPON-2 is much improved technology in PON, it upgraded not only from $10 \mathrm{Gbps}$ to $40 \mathrm{Gbps}$ but also shifting TDM to WDM multiplexing for future bandwidth demands [3]. Now the comparative analysis of various PON standards and their parameters is shown in Table 1 [4], whereas Figure 1 elucidates that every next standard of PON focusing towards improvement of data rates.

Table 1. Comparative Analysis of Various PON Standards

\begin{tabular}{|c|c|c|c|c|c|}
\hline $\begin{array}{c}\text { PON } \\
\text { Standard }\end{array}$ & $\begin{array}{c}\text { Recommended } \\
\text { By }\end{array}$ & $\begin{array}{c}\text { Downstream } \\
\text { Data (Max) }\end{array}$ & $\begin{array}{c}\text { Upstream } \\
\text { Data (Max) }\end{array}$ & $\begin{array}{c}\text { Number } \\
\text { of Users }\end{array}$ & $\begin{array}{c}\text { Bandwidth } \\
\text { Per user }\end{array}$ \\
\hline APON & ITU-T G.983.1 & $155 \mathrm{Mbps}$ & $155 \mathrm{Mbps}$ & $16-32$ & $10-20 \mathrm{Mbps}$ \\
\hline BPON & IEEE G.983.x & $622 \mathrm{Mbps}$ & $155 \mathrm{Mbps}$ & $16-32$ & $20-30 \mathrm{Mbps}$ \\
\hline EPON & ITU-T 802.3ah & $1.25 \mathrm{Gbps}$ & $1.25 \mathrm{Gbps}$ & $16-32$ & $40-80 \mathrm{Mbps}$ \\
\hline GPON & ITU-T G.984.x & $2.5 \mathrm{Gbps}$ & $1.5 \mathrm{Gbps}$ & $32-64$ & $100 \mathrm{Mbps}$ \\
\hline XGPON & ITU-T G.987.x & $10 \mathrm{Gbps}$ & $10 \mathrm{Gbps}$ & 64 & $100 \mathrm{Mbps}$ \\
\hline 10GE-PON & IEEE 802.3av & $10 \mathrm{Gbps}$ & $10 \mathrm{Gbps}$ & 64 & $100 \mathrm{Mbps}$ \\
\hline NGPON-1 & FSAN & $10 \mathrm{Gbps}$ & $2.5 \mathrm{Gbps}$ & 64 & $100 \mathrm{Mbps}$ \\
\hline NGPON-2 & FSAN & $10 / 40 \mathrm{Gbps}$ & $10 \mathrm{Gbps}$ & 64 & $100 \mathrm{Mbps}$ \\
\hline
\end{tabular}
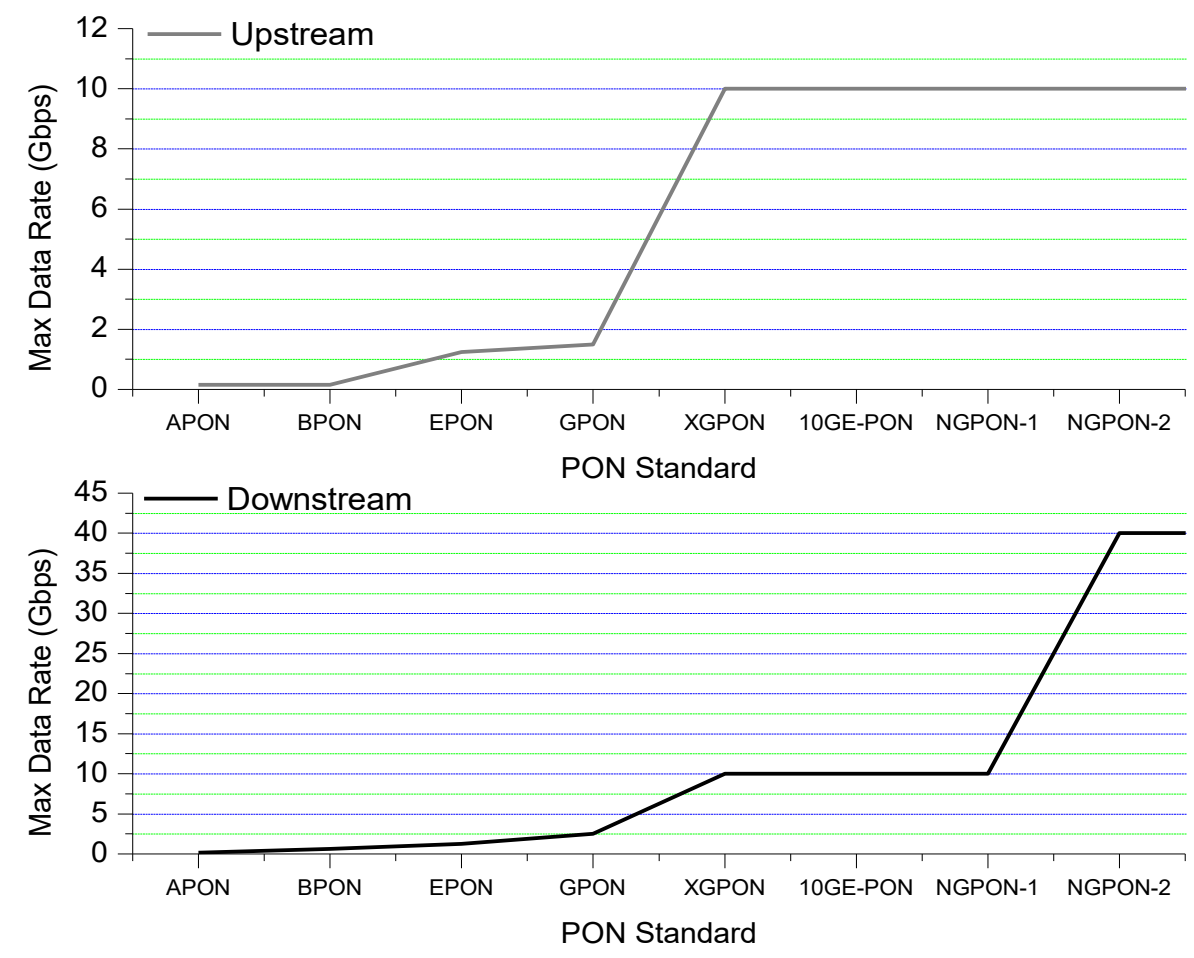

Figure 1. Maximum Data Rate in Upstream and Downstream of Different PON standards 
To achieve high data rate transmission, several advanced modulation formats have been proposed such as DQPSK with IRZ [6], RZ-DQPSK with On-Off keying (OOK) [7], Carrier suppressed RZ CSRZ-QDPSK [8], RZ-DQPSK with dispersion compensated fiber (DCF) [9], three different Differential Phase Shift Keying (DPSK) techniques and the WDM PON with semiconductor optical amplifier (SOA)[11]. But these techniques are either low data rate supported or single standard transmission based i.e. single data rate transmission furthermore only single or few WDM channels with various limitations decrease their effectiveness. However, few other techniques have been introduced for integrated standards such as coexistence of XGPON and NG-PON in [12, 13] but they support up to $10 \mathrm{Gbps}$ only. Hence, these techniques are not suitable for future challenges.

In the centralized Laser source PON, Laser is deployed in Transmitter at Optical line terminal (OLT) for downstream signal and when this signal is received at Optical Network Unit (ONU) at receiver, it is reused as a carrier for upstream data transmission and modulated by electrical data stream of customer side, this is termed as "Remodulation". Since ONU is not dependent on any specific wavelength, it is known as "Colorless ONU" which is very useful for maintenance and inventory management in PON [14-16]. Dispersion affects the performance of optical fiber. Due to these affects different types of dispersion compensators are used to enhance the performance of optical fiber. Fiber Bragg Grating (FBG) is usually used for dispersion compensation because of its low insertion loss and cost [17-19]. DQPSK is very popular for high data rate and multi-level transmission. Since it transmits 2 bits/symbol so as compared to DPSK it has half spectral occupancy but twice transmission capacity at the same symbol rate. It also has much better receiver sensitivity than intensity modulated techniques. DQPSK can also perform much better against polarization mode dispersion (PMD) and nonlinear effects because of its constant envelope [20]. IRZ is an especial case of intensity modulation technique in which optical power is available in each bit period at both the mark levels and the space levels of signal. It has double optical bandwidth as compared to NRZ. Here, it is used at ONU and the phase re-modulation is stored in the constant and high power part of the waveform, due to this IRZ modulated upstream can also work at higher extinction ratio (ER) and much better receiver sensitivity than NRZ [20].

In this paper, we have proposed and investigated mix and high data rates based 16 Channels WDM-PON which can simultaneously support both NG-PON standards. We employ DQPSK modulated downstream with 40 and $10 \mathrm{Gbps}$ data rate and IRZ based upstream having 20,10 and 2.5 Gbps data rates. FBG is used to overcome transmission impairment effects with $10 \mathrm{Km}$ fiber span in both directions. Simulative investigations of results show that simultaneous transmission of both NG-PON 1 (10 Gbps downstream and 2.5 Gbps in upstream) and NG-PON 2 (40 Gbps downstream and 20 or 10 Gbps in upstream) can be achieved successfully with good receiver sensitivity in both directions. Hence proposed noise-resilient transmission PON can simultaneously support both standards on NGPON.

\section{Working Principle \& Simulation Setup}

The proposed architecture of mix and high data rate supported NG-PON simulative design is shown in Figure 2, in which 16 High capacity WDM channels from $193.1 \mathrm{THz}$ to $194.6 \mathrm{THz}$ are used having $0 \mathrm{dBm}(1 \mathrm{~mW})$ launched power in each. In downstream transmission at OLT, these channels are modulated with mix data rate of 40 and 10Gbps DQPSK format, on the other hand for upstream transmission at ONU, IRZ modulated channels with 20, 10 and $2.5 \mathrm{Gbps}$ data rates are used and fiber span is set for $10 \mathrm{Km}$ with following parameters settings as shown in Table 2 . 


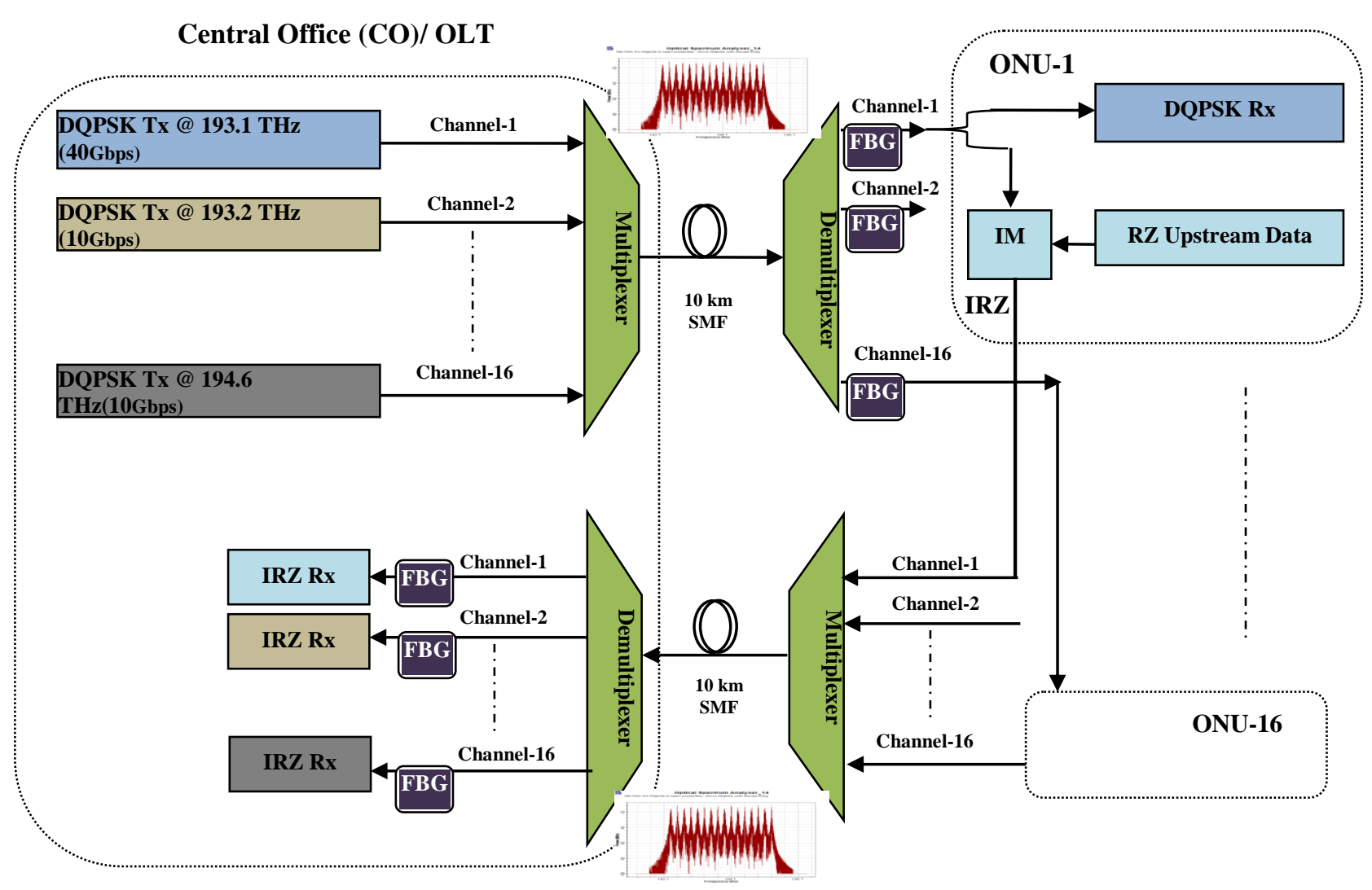

Figure 2. Working Principle and Architecture of Proposed NG-PON with FBG

Table 2. Parameters of Proposed Simulation Setup

\begin{tabular}{|c|c|}
\hline Parameters & Data \\
\hline Laser Launched Power & OdBm (1mW) \\
\hline $\begin{array}{c}\text { Data Rate of 16 DQPSK } \\
\text { Downstream Channels }\end{array}$ & $\begin{array}{c}\text { Channels } 1,3,5,7,9,11,13 \text { and } 15 \text { at } 40 \mathrm{Gbps} \\
\text { Channels } 2,4,6,8,10,12,14 \text { and16 at 10 Gbps }\end{array}$ \\
\hline $\begin{array}{c}\text { Data Rate of 16 IRZ Upstream } \\
\text { Channels }\end{array}$ & $\begin{array}{c}\text { Channels } 1,5,9 \text { and13at 20 Gbps } \\
\text { Channels 3,7,11 and 15 at } 10 \mathrm{Gbps} \\
\text { Channels 2,4,6,8,10,12,14,16 at 2.5 Gbps }\end{array}$ \\
\hline Channels Frequencies & From 193.1THz to $194.6 \mathrm{THz}$ \\
\hline Dispersion parameter & $16.75 \mathrm{ps} / \mathrm{nm} / \mathrm{km}$ \\
\hline Non Linear index-coefficient & $2.6 \times 10^{-20}$ \\
\hline Slop of Dispersion & $0.075 \mathrm{ps} / \mathrm{nm}^{2} / \mathrm{km}$ \\
\hline Effective Core Area & $80 \mathrm{um}{ }^{2}$ \\
\hline Fiber Attenuation & $0.2 \mathrm{~dB} / \mathrm{km}$ \\
\hline
\end{tabular}

All related details such as launched power, data rate, and frequency and spacing of each channel and specifications of single mode fiber (SMF) is mentioned in the Table- 2 . 
DQPSK modulated signal is generated through pre-coded data and two Mach Zehnder modulators (MZM) and IRZ signal is produced from single MZM of combined clocked signal and NRZ data. As shown in Figure 2 that WDM multiplexer and de-multiplexer are employed for channels multiplexing and de-multiplexing.

To overcome transmission impairments and fiber nonlinearity effects Fiber Bragg Grating (FBG) is placed before receiver in both directions. At ONU, power splitter separates downstream in two parts one for DQPSK receiver and other as a carrier for upstream in intensity modulator (IM). Moreover, to retrieve DQPSK signal we used Mech-Zehnder Delay interferometer (MZDI) and balanced detector and simple photo detector as an IRZ receiver. This setup is employed at receiver in twice, first one is for Inphase (I) and second one is for Quadrature-phase(Q) of DQPSK signal. Then received electrical bit stream are analyzed via Bit-error-rate analyzer to ensure successful transmission of data. Snapshot of simulation set up in Optisys software of proposed design of 16 channels PON is shown in Figure 3|

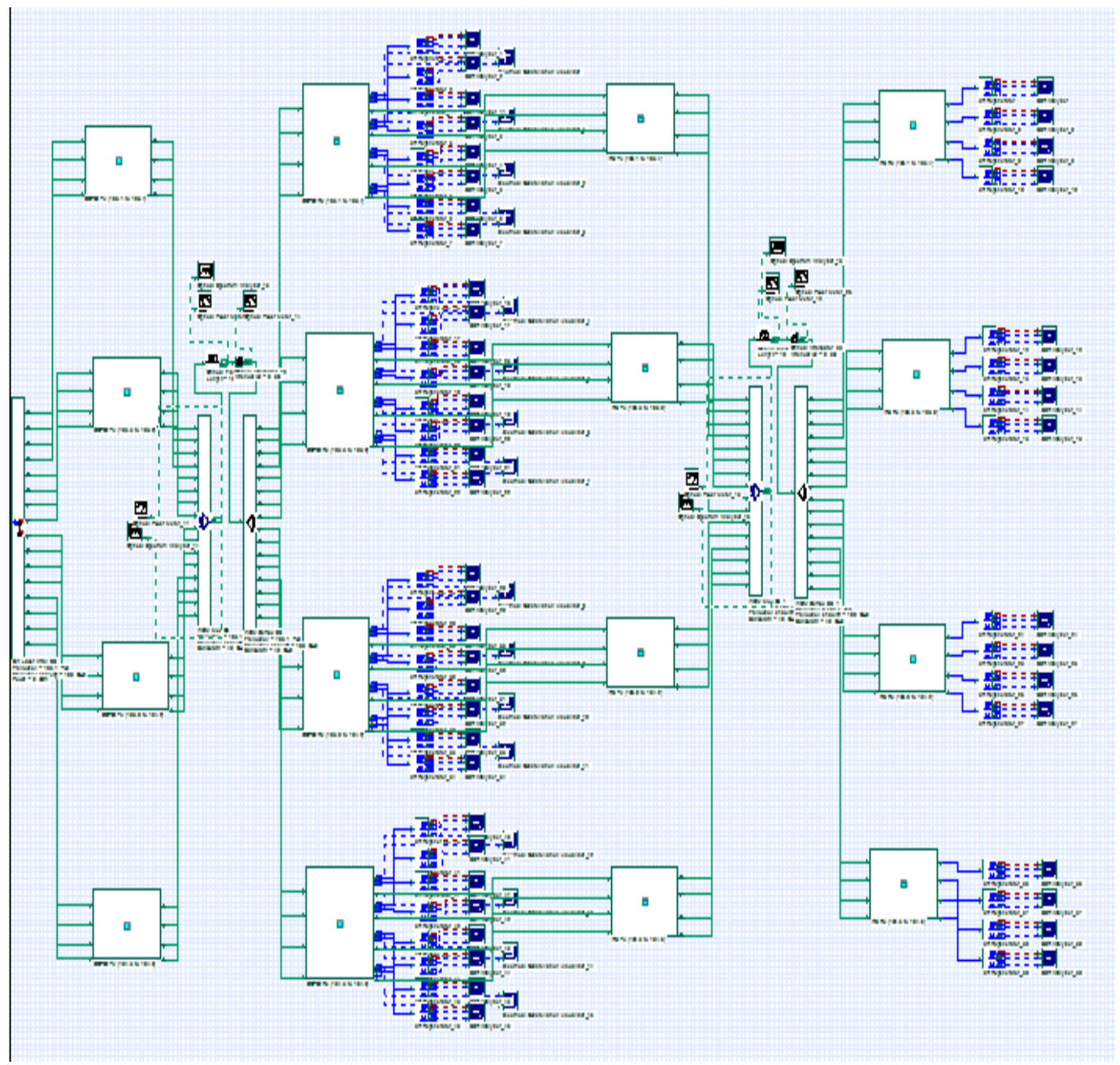

Figure 3. Snapshot of Proposed Mix data rate 16 Channels PON simulation Set up in Optisys Software

\section{Results Discussion}

It can be observed from spectrum analyzer diagrams over the fibers in proposed architecture in Figure 2 and the snapshot of simulation setup in Figure 3 that 16 channels have been employed in both directions. Since, mix data rate channels are used so we 
randomly analyzed four different channels i.e., 1, 6, 11 and 16 in both downstream as well as upstream.
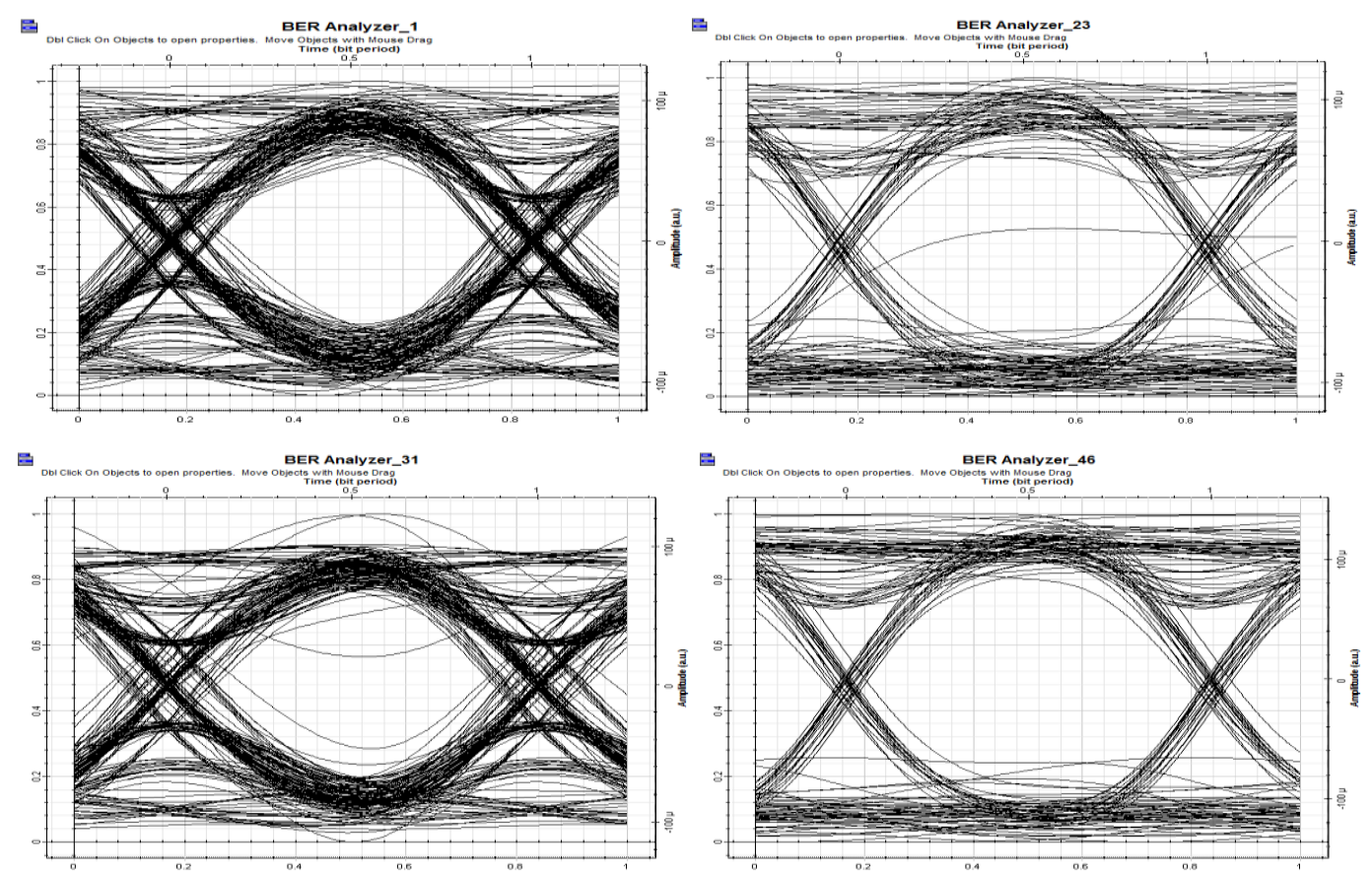

Figure 4. Eye Diagram for DQPSK Channels $1 \& 6$ on Top (from left to right) 11\& 16 Bottom (from left to right) in Proposed Downstream WDM-PON

In Figure 4 eye diagrams of selected DQPSK modulated downstream channels are shown at different data rates for $10 \mathrm{Km}$ fiber span, it can be seen that eyes diagrams are wide and open, which indicates that channels are good for transmission. Results in Table. 3 ensure the feasibility of proposed design but slight variations in results can be observed due to different data rate and position in the frequency spectrum. Therefore, channel-1 and channel-16 have better BER value because they have to face interference from one side only as first and last channels. Similarly channel-16 is better because low data rate as compared to channel-1.

Table 3. Analysis of Selected DQPSK Downstream Channels

\begin{tabular}{|c|c|c|c|}
\hline $\begin{array}{c}\text { Selected DQPSK } \\
\text { Channel \# }\end{array}$ & $\begin{array}{c}\text { Data rate } \\
\text { downstream }\end{array}$ & $\begin{array}{c}\text { Eye Height } \\
\text { @ } \mathbf{1 0 ~ K m}\end{array}$ & $\begin{array}{c}\text { BER } \\
\text { @ } \mathbf{1 0 ~ K m}\end{array}$ \\
\hline Channel-1 $(193.1 \mathrm{THz})$ & $40 \mathrm{Gbps}$ & $1.10 \times 10^{-4}$ & $8.06 \times 10^{-18}$ \\
\hline Channel-6 $(193.6 \mathrm{THz})$ & $10 \mathrm{Gbps}$ & $1.15 \times 10^{-4}$ & $1.29 \times 10^{-16}$ \\
\hline Channel-11 $(194.1 \mathrm{THz})$ & $40 \mathrm{Gbps}$ & $1.03 \times 10^{-4}$ & $1.16 \times 10^{-15}$ \\
\hline Channel-16 $(193.6 \mathrm{THz})$ & $10 \mathrm{Gbps}$ & $1.52 \times 10^{-4}$ & $3.91 \times 10^{-21}$ \\
\hline
\end{tabular}



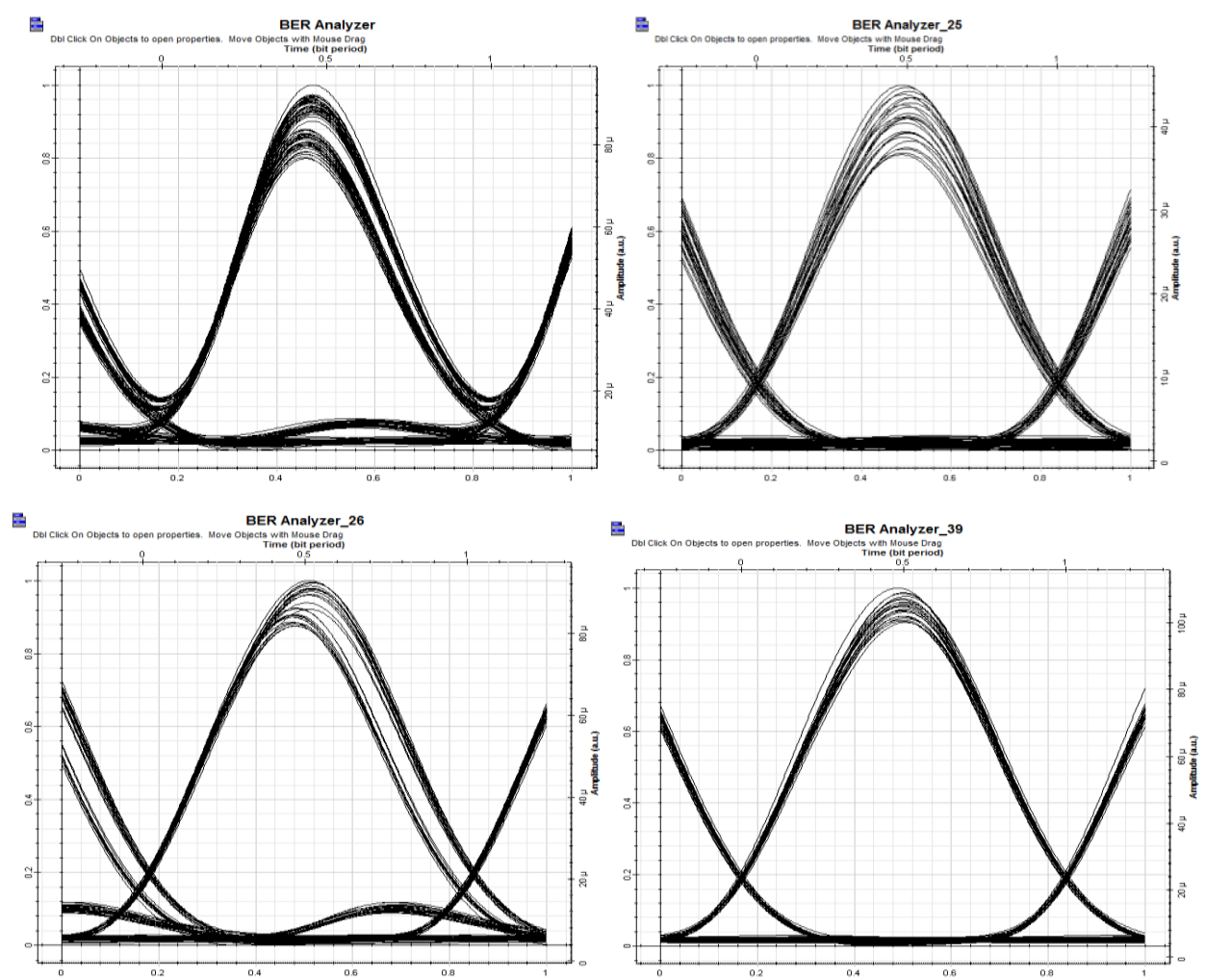

Figure 5. Eye Diagram for IRZ Channels $1 \& 6$ on Top (from left to right) $11 \&$ 16 bottom (from left to right) in Proposed Upstream WDM-PON

Similarly, eye diagrams of selected IRZ channels are shown in Figure 5, the wide and clear eye opening reflects error free transmission in upstream at different data rates channels. Feasibility of proposed design can be verified from the results in Table.4. Again, variations in result are due to different data rate and position of the channel in the frequency spectrum.

Table 4. Analysis of Selected IRZ Upstream Channels

\begin{tabular}{|c|c|c|c|}
\hline Selected IRZ Channel\# & $\begin{array}{c}\text { Data rate in } \\
\text { upstream }\end{array}$ & $\begin{array}{c}\text { Eye Height } \\
@ \mathbf{1 0 ~ K m}\end{array}$ & $\begin{array}{c}\text { BER } \\
@ \mathbf{1 0 ~ K m}\end{array}$ \\
\hline Channel-1 $(193.1 \mathrm{THz})$ & $20 \mathrm{Gbps}$ & $5.78 \times 10^{-5}$ & $1.47 \times 10^{-81}$ \\
\hline Channel-6 $(193.6 \mathrm{THz})$ & $2.5 \mathrm{Gbps}$ & $1.08 \times 10^{-4}$ & $1.12 \times 10^{-157}$ \\
\hline Channel-11 $(194.1 \mathrm{THz})$ & $10 \mathrm{Gbps}$ & $6.99 \times 10^{-5}$ & $1.92 \times 10^{-88}$ \\
\hline Channel-16 $(193.6 \mathrm{THz})$ & $2.5 \mathrm{Gbps}$ & $8.98 \times 10^{-5}$ & $3.12 \times 10^{-215}$ \\
\hline
\end{tabular}

We have further investigated the selected channels for received (Rx) power versus BER analysis in both downstream and upstream as shown in Figure 6 and Figure 7 respectively. It csan be noticed that Channel 1 and Channel 11 has higher BER values at certain received power as compared to channels 6 and 16 due to the high data rate are more effected by transmission impairment during the transmission at same fiber span. Even though receiver sensitivity of selected channels at standard bit error rate $\left(1 \times 10^{-9}\right)$ is in the range of $-30 \mathrm{dBm}$ to $-44 \mathrm{dBm}$, which is acceptable values for such a high and mix data rates transmission of 16 channels simultaneously. 


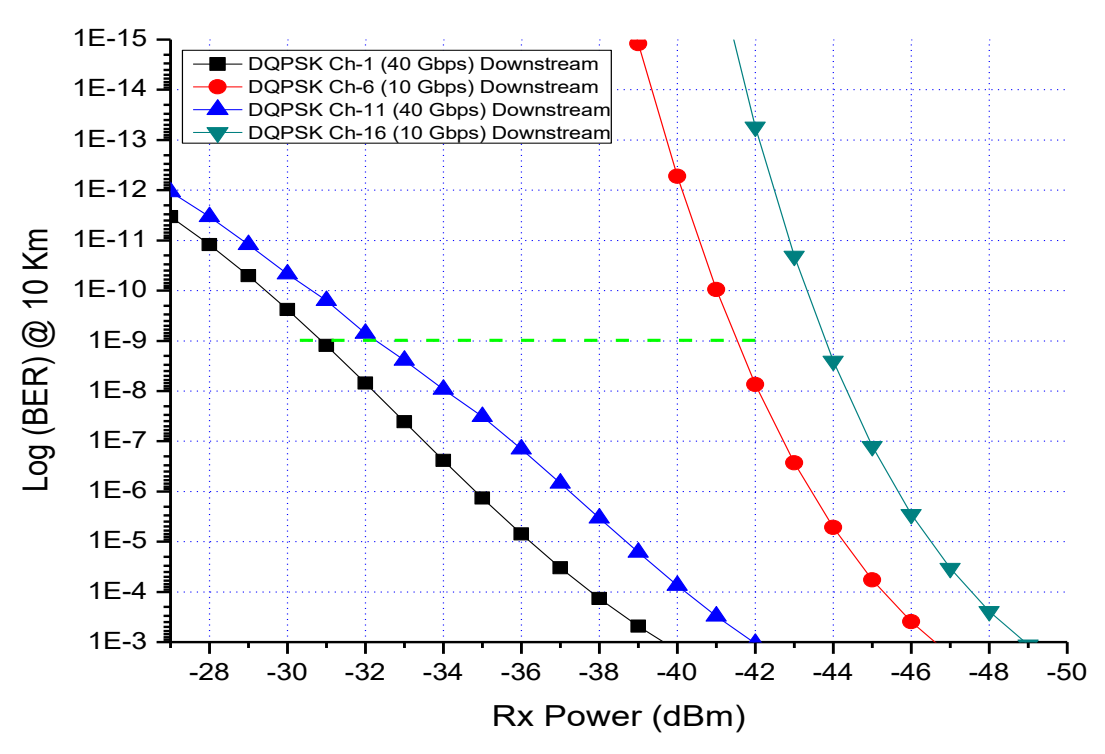

Figure 6. Rx Power Vs BER Analysis of DQPSK channels 1, 6, 11 and 16 in Downstream

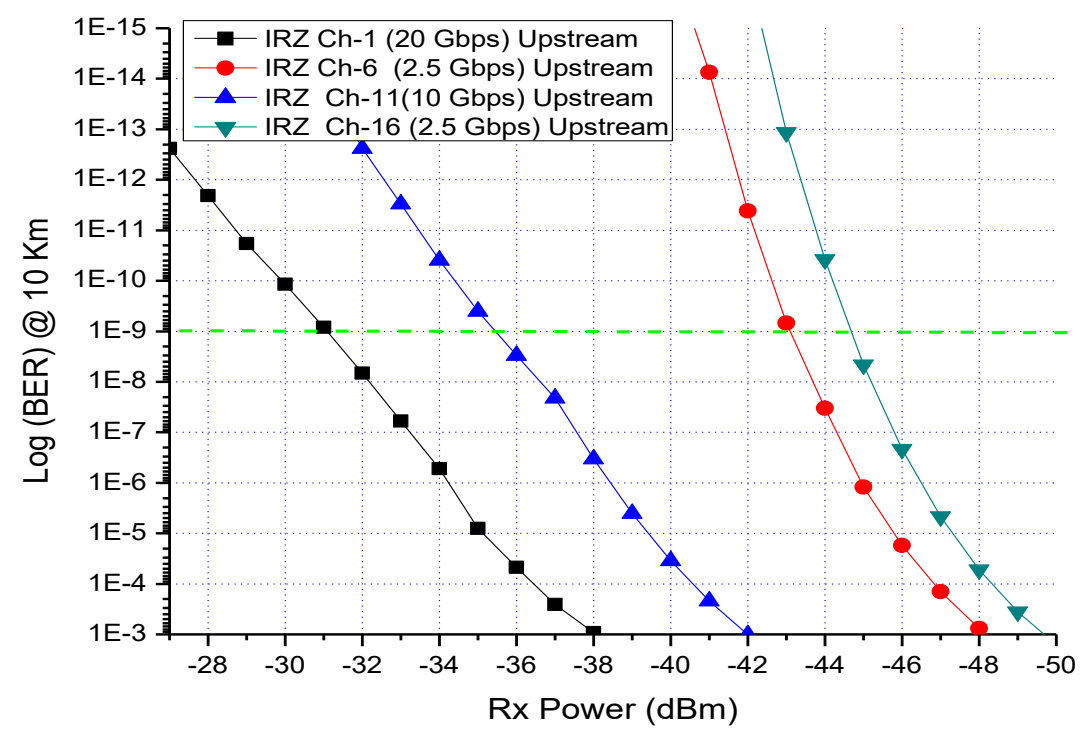

Figure 7. Rx Power Vs BER Analysis of IRZ Channels 1, 6, 11 and 16 in Downstream 


\section{Conclusion}

We proposed a mix and high data rates based 16 Channels WDM-PON which can simultaneously support both NG-PON standards. Channels number 1, 6, 11 and 16 have been investigated for BER values at different received power in DQPSK based downstream and IRZ upstream at $10 \mathrm{~km}$ fiber span. Analysis of proposed design validates technique that simultaneous high capacity transmission of 8 channels aggregated $80 \mathrm{Gbps}$ of NG-PON 1 and 8 channels aggregated 320 Gbps of NG-PON 2 in downstream are supported with lower receiver sensitivity and with acceptable range of bit errors. Hence, this technique is a feasible solution for future high data rate, high capacity, noise-resilient and simultaneous transmission of both NGPON standards.

\section{References}

[1] M. Zager, www.broadbandcommunities.com, (2017).

[2] D. Nesset, "PON Roadmap [Invited]", Journal of Opt Comm. and Networking, vol. 9, no. 1, (2017), pp. A71-A76.

[3] E. F. A. Martinez, G. P. Leguizamón and C. A. S. Fajardo, "Towards a New Generation of Passive Optical Networks", Journal Revisita Ingenieria, vol. 21, no. 1, (2016), pp. 49-62.

[4] F. Naqshbandi and R. K. Jha, "TWDM-PON-AN optical backhaul solution for hybrid optical wireless networks", Journal of Modern Optics, vol. 63, no. 19, (2016), pp. 1899-1916.

[5] J. L. Wei, K. Grobe and H. Griesser, "High speed next generation passive optical networks: performance, cost, and power dissipation", Progress in Electromagnetic Research Symp. (PIERS), IEEE, (2016).

[6] A. M. Khan, J. Zhang, Y.-L. Zhao, G.-J. Gao, S. Chen, D.-B. Wang, “A Simple and Spectrally-efficient Design of High Capacity Hybrid WDM/TDM-PON with Impro Receiver Sensitivity", JCUPT, vol. 20, no. 3, (2013), pp 114-120.

[7] A. Chenika, A. Temmar and O. Seddiki, "A Novel architecture of an optical high-speed access network WDM-PON using NRZ-DQPSK/ASK modulation”, ICNCRE, (2013), pp. 396-398.

[8] R. Chitravelu and G. M. Muthu, "Performance evaluation of simple CSRZ-QDPSK transmitter configurations for 20-Gbps PON applications", Turkish J. Elect. Engg. \& Comp. Science, (2016).

[9] V. Tiwari, D. Sikdar and V. K. Chaubey, "Performance optimization of RZ-DQPSK modulation scheme for dispersion compensated optical link", Optik vol. 124, (2013), pp. 2593-2596.

[10] W.-H. Jiang, L. Jiang, S.-F. Tong and X.-Y. Li, "Differential phase shift keying in the research on the effects of type pattern of space optical communication system", ICCMCEE, (2013), pp.1376-1380.

[11] J. J. Martínez, N. Merayo and A. Villafranca, "WDM-PON Network Upscaling Using in-Building Linear SOAs", ICTON, (2011).

[12] D. Mraković, “Analysis of Coexisting GPON \& NGPON1 Systems”, Telfor Journal, vol. 3, no. 1 (2011), pp. 43-48.

[13] J. Müllerová, D. Korček and M. Dado, "On wavelength Blocking for XG-PON Coexistence with GPON and WDM-PON Networks", ICTON, (2012).

[14] A. M. Khan, J. Zhang, Y. Zhao, Y. Khan, A. Latif and J. Han, "A Cost-effective and Spectrallyefficient Design of Centralized Light Source WDM-PON using Aggregated $160 \mathrm{Gbit} / \mathrm{s}$ DQPSK Modulation for Downstream and Re-modulated IRZ for Upstream Transmission”, Advances in Info Sciences \& Service Sciences (AISS), vol. 5, no. 3, (2013), pp. 305-312.

[15] A. M. Khan, Z. Jie, Y. Khan, M. Idress, Y.-L. Zhao, S. Niazi, A. Husein, A. Munir, I. Ahmed and J.-Y. Liu, "A Simple and Cost-effective Design for Simultaneous Transmission of Point-to-point and Broadcast Services in WDM-PON”, Int. Journal of Future Gen Comm. \& Net., vol. 6, no. 3, (2013), pp. 41-56.

[16] L. Li and D. Zhao, "Performance of Phase Modulation in WDM-PON Transmission System", Journal of Optical Communications, vol. 36, no. 1, (2015), pp. 57-65.

[17] P. K. Raghav and R. Chaudhary, "Compensation of Dispersion in 10 Gbps WDM System by Using Fiber Bragg Grating”, IJCEM Int. Journal of Computational Engg \& Mang., vol. 15, no. 5, (2012).

[18] J. Islam, S. Islam, M. Rahman and Rokanuzzaman, "Dispersion Compensation in Optical Fiber Communication Using Fiber Bragg Grating", Global Journal of researches in Electrical \& Electronics Engg., vol. 12, no. 1, (2012).

[19] O. Arora and A. K. Garg, "Impact of Fiber Bragg Grating As Dispersion Compensator on the Receiver Characteristics", Global Journal of researches in engineering Electrical and electronics engineering, vol. 11, no. 7, (2011). Version 1.0.

[20] A. M. Khan, J. Zhang, Y. Zhao, Y. Khan, M. Idrees, L. Wang and M. Ahmed, "A Cost-effective and Rayleigh Backscattering Noise-resilient Design of Single Fiber Centralized Light Source WDM-PON with Improved Receiver Sensitivity”, JCIS, Hong Kong, vol. 9, no. 2, (2013), pp. 749-756 


\section{Authors}

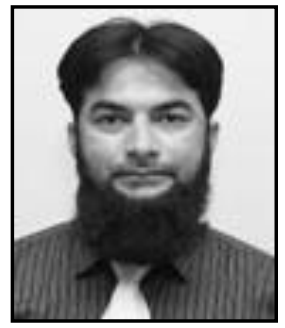

Ahmed Muddassir Khan, he has completed his early education from prestigious institutes of Pakistan with distinctions. He completed B.E. (Electronics) from Mehran University Jamshoro, M.Engg. (Telecommunication) from NED University, Karachi and MBA from Federal Urdu University, Karachi. He started his professional career as a Telecom Engineer in Pakistan's leading Telecom organization (PTCL) and gained vast field and research experience in high capacity optical networks. Then he started $\mathrm{PhD}$ from Beijing University of Posts and Telecommunication (BUPT), Beijing, China. His research based on implementation of Robust Advanced Modulation Formats for Cost effective and High capacity Next Generation Passive Optical networks (PON). He has completed $\mathrm{PhD}$ with several research publications in esteemed international research journals. Currently, he is working in Indus University, Karachi, as an Associate Professor and Chairperson of Department of Electrical Engineering in Faculty of Engineering, Science and Technology (FEST). He also has other important academic role and responsibilities in Indus University such as Chair of BOS, member of BOF, Academic Council, and R\&D Committee. He is an approved $\mathrm{PhD}$ supervisor and selected as an NTC Program evaluator by higher education commission (HEC), Pakistan. He is also member of different national and internal societies and speaker in different research forums. He served as an organizing committee and technical Co-chair in IEEE ICIEECT 2017. He also has successfully supervised ICT R\&D funded projects His core research areas are Optical Communication, DWDM, GPON, Hybrid WDM/TDM-PON, Submarine Optical Fiber Cable Networks, Advanced Modulation Formats and Next Generation Passive Optical Networks (NGPON).

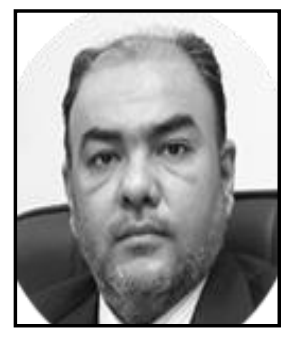

Sayed Hyder Abbas Musavi, $\mathrm{He}$ is $\mathrm{PhD}$ and $\mathrm{ME}$ in Telecommunication Engineering under HEC Scholarship and B.E. in Electronics Engineering from Mehran University of Engineering and Technology, Pakistan. He is currently serving as Dean Faculty of Engineering Science and Technology Indus University Karachi. Previously he was engaged as Chairman Department of Electrical and Electronics Engineering Hamdard University Karachi. In past he has served as Professor and Principal at Petroman- an Institute of Ministry of Information Technology and Telecommunications, Government of Pakistan at its various campuses for more than 10 years and had also remained Executive District Officer IT (EDO-IT) District Government Larkana. To his credit are more than 30 research publications in national and international journals. Dr. Musavi has attended numerous international conferences as invited speaker. He is on review board of two impact factor international journals. He is member of numerous national and international societies including member IEEEP Karachi local council, IEEE, IEEE Computer society, IEEE Signal Processing Society, IEEE Devices and Circuits Society, IEEE Communications Society etc. He was General Chair in IEEE ICIEECT 2017. 


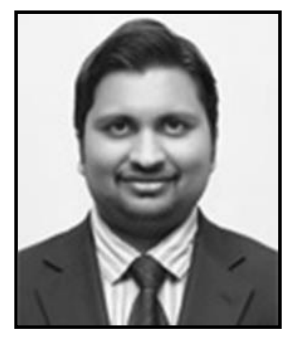

Areez Khalil Memon, He has done B.E(Electronics) from Mehran University of Engineering and Technology, Jamshoro, Sindh, Pakistan (Jan, 2006 - March, 2010) and Masters From University of Leicester, United Kingdom (UK) in MSc Advanced Electrical and Electronics Engineering. Currently, he is doing $\mathrm{PhD}$ in Electrical Engineering from Indus University, Karachi. He has 15 research publications in conferences, IEEE proceedings and journal. A part from his teaching and research activities he is also a member of Board of Studies and Board of Faculty in Indus University. He has good knowledge of Renewable Energy, Electrical Machines, Control Engineering and PON.

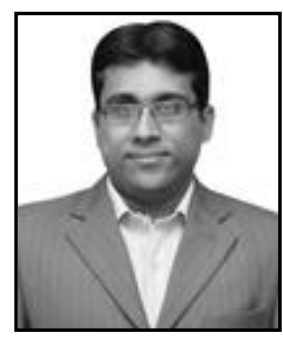

Munsif Ali Jatoi, He has completed his $\mathrm{PhD}$ (Electrical and Electronic Engineering) from Universiti Teknologi PETRONAS, Malaysia in 2016. Prior to this, he has completed M.Sc. (Advanced Photonics and Communications) from The University of Warwick, UK and B.E. (Electronics) from Mehran University of Engineering and Technology, Jamshoro, Pakistan in 2009 and 2007 respectively. Dr. Jatoi has more than 7-years of teaching experience locally and internationally in the capacity of Assistant Professor, Lecturer and Graduate Assistant respectively. He has total 19 journals and conferences at his credit. He has presented his research work in various international exhibitions and won two silver medals for his performance in ITEX and SEDEX in Malaysia. Dr. Jatoi has filed 5 patents in the field of EEG source localization and has co-authored a book chapter with CRC Taylor in Francis, US. His research interests are brain signal processing, EEG inverse problem, Epilepsy prediction, brain connectivity and applied mathematics for neuroscience.

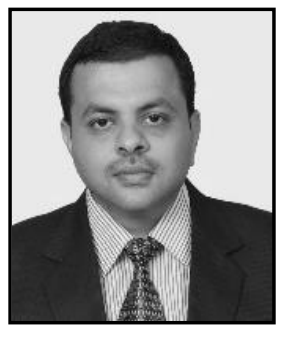

Syed Shahzeb Sami, He completed his early education from prestigious institutes of Pakistan with distinctions. He had completed BS (Electronics) from Sir Syed University, Karachi, M.Engg.(Electronics) \& M.Engg.(Mechatronics) from NED University Engr. Syed Shahzeb Sami is currently working as an Assistant Professor and Program Coordinators in Indus University, Pakistan. He is member of different statutory bodies like $\mathrm{BoS}$ and $\mathrm{BoF}$ at Indus University. He has supervised many industrial funded projects and published different research articles in journals. His core research area is Robotics, Industrial Electronics, Electromechanical Systems and Opto-electronics Communication.

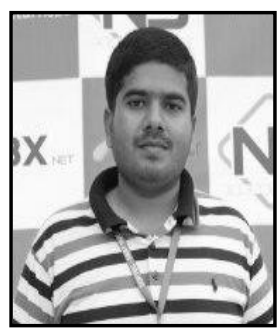

Faizan ur Rehman, Computer Systems Engineer from COMSATS Institute of Information Technology (CIIT) Wah Cantt and Masters in Electrical Engineering from National University of Computer and Emerging Science (NUCES-FAST) Lahore. He is currently working at Indus University Karachi as a Lecturer. His areas of research are Next Generation Passive Optical Networks and Speaker Recognition System. 
International Journal of Future Generation Communication and Networking Vol.10, No.9 (2017) 